\title{
O ABUSO DE SUBSTÂNCIAS TÓXICAS NA ADOLESCÊNCIA: UMA TENTATIVA DE INCORPORAÇÃO DO OBJETO?
}

Silvia Maria Abu-Jamra Zornig

Silvia Maria Abu-

Jamra Zornig

Psicanalista da

Sociedade de

Psicanálise Iracy

Doyle; professora

do programa de

Pós-Graduação

em Psicologia

Clínica da PUC-

Rio; coordenadora

do Curso de

Especialização em

Psicologia com

Crianças da PUC-

Rio.
RESUMO: Procura-se discutir a função do objeto na adolescência a partir de um fragmento clínico em que a relação aos objetos se dá por uma lógica incorporativa que impede o acesso às experiências de introjeção e aos processos de simbolização. Apesar de a adolescência ser definida por alguns autores psicanalistas como um momento lógico de apropriação subjetiva e confronto com a castração e a finitude, este texto procura ressaltar a importância do acompanhamento 'vivo' do analista para que o investimento do vazio possa se dar sem angústia de aniquilamento.

Palavras-chave: Adolescência, psicanálise, simbolização, introjeção, incorporação.

ABSTRACT: The abuse of toxic substances in adolescence: an attempt to incorporate the object? This paper aims at discussing the role of the object in adolescence through a clinical vignette where the relationships to the objects are done through an incorporative fashion that prevents the access to the experiences of introjection and symbolization. Even if adolescence is defined by some psychoanalysts as a logic moment of subjective appropriation and confrontation to castration and finitude, this paper attempts to emphasize the importance of the "live" companionship of the analyst in order to open the path toward the libidinal investment of the void without annihilation anxiety.

Keywords: Adolescence, psychoanalysis, symbolization, introjection, incorporation. 
A reflexão sobre o estatuto do objeto na adolescência aponta para um paradoxo importante, pois a adolescência é ao mesmo tempo um momento de confronto com a alteridade e com a solidão subjetiva como possibilidades criativas de existir no mundo, mas também um tempo em que as falhas nas relações com os objetos primordiais podem ser atualizadas em vivências de desamparo e fragmentação.

Assim, se a adolescência é um momento lógico — e não cronológico — de apropriação subjetiva do sintoma que a criança era no discurso parental (RASSIAL, 1999), quando o confronto com a diferença e a falta são elementos essenciais ao trabalho de subjetivação, na clínica este trabalho muitas vezes é interrompido por uma identificação melancólica como defesa contra a perda do objeto, perda vivenciada não como investimento do vazio (GREEN, 1988), mas como uma falta a ser, que aponta para uma falha na função simbolizadora do objeto primordial (ROUSSILLON, 2010).

Este trabalho procura discutir a relação entre o uso abusivo de substâncias tóxicas na adolescência (álcool e psicotrópicos), e as falhas nas relações com os objetos primários que dificultam a instauração dos limites entre o eu e o outro e, consequentemente, a internalização do objeto como estrutura enquadrante (URRIBARRI, 2010). Apesar de esse uso poder ser paradoxalmente um exercício de transicionalidade, na tentativa de separação de um objeto tóxico interno, pode apontar também para uma passagem ao ato, marcada pela sedução da volta ao estado zero de tensão — narcisismo negativo na aspiração ao não ser.

A aspiração ao não ser, à volta a um estado zero de excitação, é definida por Green como uma descatexia radical que impede os processos de simbolização e o sentimento de continuidade de existência, e é justamente a mediação do objeto que possibilita a passagem da vacuidade que leva à morte psíquica à construção de um espaço protetor que permita a experiência de silêncio e não comunicação como estruturante e não mortífera (GREEN, 1988, p.60).

Nesta perspectiva, a importância da presença em reserva do analista (FIGUEIREDO, 2007) será o eixo de nossa reflexão teórico-clínica ao propor que a clínica psicanalítica com adolescentes pressupõe um acompanhamento presente, mas não intrusivo, que possibilite a vivência de ausência e o confronto com a alteridade sem ameaça à integridade psíquica do sujeito.

O termo "acompanhamento" segue uma indicação winnicottiana que parece muito apropriada para o processo psicanalítico na adolescência, como a possibilidade de um acompanhamento de uma crise que não está lá para ser curada, mas para ser desenrolada e vivenciada, tendo o analista como presença não intrusiva. Esta presença em reserva reabre a questão da presença e ausência do objeto, agora diante de uma nova perspectiva, a perspectiva de "jogar" com a ausência, fazendo uma catexia positiva do vazio, como propõe Green. No entanto, 
se o analista não conseguir sustentar a posição de testemunha, permitindo que a encenação (a mensagem veiculada pelo corpo e pela ação) seja experimentada e endereçada ao outro, há o risco de o sujeito utilizar mecanismos de defesa mais primários como estratégias de proteção psíquica.

M. Khan, num belíssimo artigo intitulado “Ouvir com os olhos” (1971/1974) ao discutir a problemática não neurótica, distingue entre uma clínica do conflito e da confrontação — própria à neurose — e uma clínica da problemática limite em que imperam os mecanismos da cisão e da clivagem. O autor enfatiza a diferença no manejo clínico, pois enquanto no conflito neurótico a pessoa sabe inconsciente ou conscientemente da existência dos dois lados da equação, nos estados dissociados ela fica totalmente envolvida com cada aspecto, figurando-os no corpo. "A encenação exige uma testemunha que a experimente e informe. A atuação procura cúmplices para descarga e satisfação” (KHAN, 1971/1974, p.302).

Esta indicação permite articular a adolescência a uma "situação fronteiriça (CARDOSO, 2001), na qual a dimensão narcísica e alteritária reaparece, ligada à problemática dos limites intra e intersubjetivos. Nesta perspectiva, o lugar de testemunha e de acompanhamento do analista é fundamental para propiciar a transformação da descarga pulsional em endereçamento ao Outro, num possível acesso aos processos de simbolização e síntese.

No caso de abuso de substâncias tóxicas (álcool e psicotrópicos) que ilustraremos a seguir, observa-se uma falha nos processos de introjeção e no papel de mediação atribuído ao objeto, tendo como consequência a impossibilidade do sujeito de vivenciar a escansão entre presença e ausência do outro, sem se sentir ameaçado por angústias primitivas de aniquilamento. Por outro lado, a tentativa de manter o objeto incorporado como defesa contra o reconhecimento de sua ausência mantém o sujeito aprisionado a uma dependência patológica que prejudica o trabalho de luto e o consequente acesso à reflexividade, provocando um curto-circuito que muitas vezes impulsiona o sujeito a uma passagem ao ato.

É neste contexto que o enquadre se torna fundamental para propiciar a instauração de um espaço 'ventilado' entre sujeito e objeto, que permita o acesso aos processos de simbolização. Lembremos Winnicott ao indicar que o adolescente pode ser descrito "como um isolado" e que a preservação do isolamento pessoal faz parte do "estabelecimento de uma técnica pessoal de comunicação que não leve à violação do self central” (WINNICOTT, 1963/1990, p.173). Assim, alerta que a psicanálise pode ser um "estupro espiritual” para o adolescente, se o analista não aceitar que a comunicação se origina do silêncio e que a crise da adolescência deve ser acompanhada, e não curada.

Ogden propõe a noção de intersubjetividade analítica ao enfatizar a simultaneidade da dialética entre unicidade e dualidade, destacando que nenhum destes polos existe em forma pura, mas num interjogo que produz um 'entre', 
um terceiro analítico, construído pelo analista e pelo analisando simultaneamente (OGDEN, 1995). Green corrobora esta ideia ao propor a noção de "objeto analítico" como um objeto terceiro produzido pela comunicação entre analista e analisando.

Nesta perspectiva, o trabalho analítico se apoia sobre um eixo diferente do eixo clássico de interpretação e representação, pois o contexto analítico (situação analítica) deixa de ser silencioso, como no caso do tratamento dos conflitos neuróticos, e se torna presente como espaço transicional que abrange o funcionamento mental do analista e as sensações e afetos do analisando (GREEN, 1988).

Esta indicação nos parece fundamental para pensar o trabalho analítico na adolescência como um momento de 'entre', em que o analista precisa ficar num lugar suficientemente semelhante para propiciar ao sujeito a experiência de brincar com as identificações, mantendo-se, no entanto, como outro sujeito, para que a análise funcione como interpelação ao adolescente sobre a dimensão enigmática da alteridade (ROUSSILLON, 2010).

Roussillon propõe uma definição interessante para o termo 'intersubjetivo' ao indicar que este se refere a um "encontro entre um sujeito atravessado pulsionalmente e com uma vida psíquica inconsciente, e um objeto que também é um outro sujeito que também é animado por uma pulsionalidade, parte da qual é inconsciente" (ROUSSILLON, 2008, p.2, tradução livre). Assim, a noção de intersubjetividade fica referida a uma relação que possibilita que o objeto reflita para o bebê seu potencial criativo de forma especular, mantendo-se, no entanto, como um outro-sujeito. O autor ressalta a função simbolizadora do objeto nos primórdios da subjetivação à medida que sua presença qualitativa permite ao sujeito iniciar os processos de simbolização, ao mesmo tempo que seu estatuto como outro-sujeito — que poderíamos aproximar da noção de "significantes enigmáticos" proposta por Laplanche — impede um estado confusional ou fusional, pois há sempre algo no objeto (sexual e inconsciente, desconhecido dele mesmo) que interpela e convoca o sujeito a um trabalho de elaboração (LAPLANCHE, 1992).

Esta definição pode ser utilizada também para a adolescência se colocarmos a ênfase na noção de um objeto que é outro-sujeito, ou seja, no reconhecimento da alteridade do objeto, sem que esse reconhecimento seja vivenciado como um vazio insuportável. Para que esta dimensão intersubjetiva seja possível, é necessário fazer o luto da ilusão de completude narcísica, da fantasia de "um corpo para dois" (McDOUGALL, 2000).

Mas de que luto se trata na adolescência? De um luto que permite o abandono, ainda que relativo, da dependência ao outro, que é uma das características da infância? Um luto de uma imagem inconsciente do corpo infantil? Um luto como possibilidade de internalização, de representação, de uma necessária 
solidão subjetiva? Um luto de ter que se destacar do lugar de semblante de objeto de desejo do desejo do outro? Um luto que permite o acesso à genitalidade e à escolha objetal?

Freud, em Luto e melancolia (1917/1976), propõe uma diferenciação entre o trabalho do luto e a metapsicologia da melancolia, indicando que enquanto no trabalho de luto o sujeito procura elaborar a perda de um objeto, identificando-se a traços parciais do mesmo, na melancolia há algo do objeto que foi perdido, mas não se sabe exatamente o quê. Assim "a sombra do objeto recai sobre o eu”, fazendo com que o sujeito se torne o próprio objeto, impedindo sua perda e consequente representação (FREUD, 1917/1976, p.249).

Roussillon retoma esta concepção freudiana de identificação melancólica para subverter a lógica freudiana, colocando a ênfase na "sombra" do objeto, propondo que sombra aponta para aquilo que o objeto não pode refletir para o sujeito sobre ele mesmo, que não esteve lá para ser simbolizado, que tem a dimensão de vazio, de um olhar que trespassa o outro e que não teve função de espelho. Assim, segundo o autor, o pensamento está diante de um paradoxo: "para simbolizar é necessário e suficiente fazer o luto da coisa, mas para fazer o luto da coisa é preciso representá-la e simbolizá-la" (ROUSSILLON, 1999, p.223, tradução livre).

Este paradoxo é interessante, pois aponta para a dupla face da função simbolizadora do objeto: se a simbolização pressupõe a saída de uma especularidade pré-simbólica e o reconhecimento da alteridade (a função do terceiro), este processo só pode ocorrer com a necessária presença do objeto. Assim, se o processo de adolescer se define por um trabalho de luto frente ao reconhecimento da castração e da incompletude, os remanejamentos identificatórios que este momento produz e a reativação de conflitos pré-edípicos podem trazer à tona fragilidades narcisico-identitárias relacionadas a falhas na relação ao objeto primordial que favoreceriam não um trabalho de luto e de introjeção, mas sim uma lógica da incorporação como identificação melancólica.

O conceito de Ferenczi (1912/1955) sobre a introjeção é primoroso por definir o mecanismo de introjeção como "uma extensão ao mundo externo dos interesses originalmente autoeróticos, através da inclusão de seus objetos no ego" (FERENCZI, 1912/1955, p.316, tradução nossa) ou, em outras palavras, como a objetalização do autoerotismo. Segundo o autor, todas as formas de amor objetal são uma introjeção, uma ampliação do Eu.

Abraham e Torok desenvolvem melhor esta ideia ao criticar a tendência na psicanálise de se considerar as noções de introjeção e incorporação como sinônimos. Para os autores, o conceito de introjeção proposto por Ferenczi não se refere a uma possessão incorporativa do objeto através de sua perda, mas justamente o oposto, pois enfatiza a função de mediação do objeto que, por sua presença, possibilita a inclusão dos processos inconscientes e das experiências pulsionais 
no Eu. A incorporação seria justamente o mecanismo fantasístico contra a perda do objeto através de sua instalação no interior do sujeito. A identificação melancólica se daria via incorporação, ou seja, como uma impossibilidade de introjeção (ABRAHAM \& TOROK, 1987).

Este modelo de introjeção pressupõe não uma incorporação do objeto, mas a introjeção das experiências vivenciadas pelo sujeito, explorações de seu corpo, sentidas na presença do outro materno. Assim, mesmo se nos primórdios do psiquismo, incorporação e introjeção se confundem, a indicação de Abraham e Torok é precisa por ressaltar que a diferença entre os dois processos se dá pela qualidade da função do objeto. A presença implicada do objeto possibilita que a boca cheia, repleta pelo seio possa gradualmente passar a uma boca vazia, a experiências que permitam ao sujeito representar as experiências com o objeto sem procurar mantê-lo via incorporação como uma recusa a perdê-lo. Nesta perspectiva, os autores indicam que enquanto a introjeção põe fim à dependência ao objeto, a incorporação reforça o vínculo original.

\section{FRAGMENTO CLÍNICO}

O caso de Maria não só nos permite refletir sobre uma lógica da incorporação através do abuso de álcool e psicotrópicos na adolescência, como coloca em questão um fenômeno clínico frequente, o de análises que se iniciam na infância e são retomadas na adolescência, a partir de sintomas depressivos.

É interessante notar que durante o processo analítico de Maria, iniciado com a construção de uma neurose infantil como forma de instauração de uma triangulação e de uma posição subjetiva (ZORNIG, 2008), ocorre um recuo narcísico precipitado pela separação dos pais no início da adolescência, o que faz com que sua relação aos objetos seja vivenciada por meio de uma prática descomedida de sexo e drogas que pouco a pouco dá lugar a abuso de álcool e comprimidos que a colocam numa posição estereotipada de excessiva, de sem limites, numa temporalidade da ação.

Freud, na discussão do caso do pequeno Hans, pontua que as histerias de angústia (fobias) são por excelência as neuroses da infância por seu caráter móvel, que faz com que a angústia se fixe numa representação substitutiva, e por aparecerem desde muito cedo na vida da criança (FREUD, 1909/1975, p.116). O autor sugere que as histerias de angústia têm também caráter estruturante por permitirem à criança elaborar as vicissitudes e conflitos de seu percurso edípico sem sofrerem o impacto maciço do recalcamento. Assim, o sintoma da criança pode ser pensado como uma tentativa de mediação entre ela e seus objetos primordiais, e a constituição da neurose infantil como ponto culminante da organização psíquica do sujeito. 
Assim, as neuroses na infância poderiam ser definidas como a matéria-prima do infantil — infantil que não se reduz à infância cronologicamente vivida, mas que se mantém como produção fantasística do sujeito sobre sua própria infância (ZORNIG, 2008).

Maria, com 7 anos, é trazida por sua mãe à análise em função de medos de fantasmas e objetos extraterrestres, que se traduzem em recusa a sair de perto da mãe e de frequentar o colégio. Nas entrevistas iniciais a mãe relata ter escondido do marido a procura de análise para a filha, por achar que ele não concordaria que "havia algo de errado com ela”. O pai é descrito como ausente, autoritário, workaholic, explosivo, um pai que não se envolve afetivamente com a filha ou com a mulher, reforçando uma lógica dual e claustrofóbica entre Maria e sua mãe, que toma a criança como um objeto que tampona toda a problemática de sua relação conjugal.

Ao funcionar como um elemento terceiro que se interpõe a ela e à mãe, a análise é vista ao mesmo tempo como salvaguarda de sua integridade como sujeito, mas também como um risco potencial que ameaça o gozo sintomático de ficar colada ao outro: ante a angústia de separação, a mãe propõe como solução incestuosa a compra de uma cama de casal para dormir com a filha, interrompendo sua análise assim que a criança inicia um processo de individuação e separação.

Cabe aqui retomar a indicação de Abraham e Torok referente à incorporação, pois a mãe de Maria reforça a fantasia de um corpo para dois ao se oferecer como objeto de incorporação, tomando a filha como seu par, sem nenhuma mediação que pudesse propiciar a introjeção de experiências de ausência na presença do objeto.

O pai não consegue encarnar a função simbólica de limite ao desejo materno, oscilando entre uma omissão, vivenciada por Maria como abandono e desinvestimento, e uma presença violenta que coloca em risco suas tentativas de subjetivação.

Podemos dizer que não há constituição da neurose infantil, pois não é possível a instauração de um sintoma que tenha a função estruturante de se interpor à criança e ao outro. Ao contrário, a triangulação edípica perde o caráter de abertura aos processos de representação para funcionar numa lógica de 'bi-triangulação’. Conforme sugere Green, o termo bi-triangulação indica que o sujeito está lidando com um aparente triângulo que na verdade forma uma entidade, como duas faces da mesma moeda: o objeto bom é sempre inacessível, levando à depressão, enquanto o objeto mau é intrusivo e mobiliza muitos recursos do ego para combater essa perturbação. O importante é que esta forma de relação ao objeto impossibilita a constituição de uma ausência e bloqueia a capacidade de pensar (GREEN, 1988, p.47). 


\section{UM MUNDO SEM LIMITES}

Maria retorna aos 14 anos, logo após o divórcio dos pais, relatando enorme tristeza, vontade de morrer, desânimo e preocupação extrema quanto a contrair doenças graves, como Aids ou câncer. Este segundo tempo da análise é marcado por um questionamento em relação à identificação com a mãe, quando ela se pergunta se corre o risco de ficar também uma pessoa só e sem amigos. O medo de morrer é associado ao desejo de vingar-se da mãe, de fazê-la sofrer com sua perda, esta mãe "que só vive para ela" (sic), recurso radical para separar-se desta dialética dual. O pai, agora numa situação financeira estável, lhe dá muito dinheiro, dinheiro demais, de que ela não precisa. Por exemplo, quando ela lhe pede dinheiro para um lanche, ele lhe dá $\mathrm{R} \$ 200,00$ e quando ela responde que "é muito", ele lhe diz para ficar com o troco. Não há nenhuma dívida a ser reconhecida, mas só uma lógica do descomedido e do excesso que provoca em Maria uma tentativa de instaurar em si a função paterna, colocando limites a seu comportamento e atuação: não usa o cartão de crédito sem limite que o pai lhe dá, estipula para si própria horários de retorno para casa, mesmo sem ter hora para voltar, e assim por diante.

Neste momento, a mãe decide novamente interromper a análise da filha, sob a alegação de não ter mais dinheiro. Cria-se um impasse: para continuar o tratamento é necessário aceder ao pai, mas Maria, mesmo afirmando querer continuar em análise, não concorda em deixar que o pai participe de seu tratamento, dizendo: "não posso contar a meu pai". "Contar que você sofre”, indaga a analista? "Exatamente", responde, "ele acha que sou uma princesinha que tem tudo e deve ser feliz".

A "princesinha" retorna aos 16 anos dizendo que seu motivo para voltar a fazer análise é o casamento do pai com uma moça "quase” tão nova quanto ela. O casamento coloca em evidência uma fantasia incestuosa que é o motor para uma conduta de adição: inicia sua vida sexual com celebridades, num comportamento que se assemelha ao consumo de drogas, por levá-la a um clímax sem orgasmo - clímax por conseguir causar o desejo de seus ídolos tão desejados, mas uma previsível incapacidade de reconhecer seu direito ao prazer que o outro poderia lhe proporcionar. A relação dita sexual indica a busca de uma gratificação narcísica que se exprime na frase: "ele me escolheu porque sou especial", como se a ilusão de completude nesse desencontro sexual fosse sempre atuada para denunciar sua impossibilidade. Assim, sua vida se divide em altos e baixos: intensidade e excitação nos shows de rock, na conquista dos roqueiros, e apatia e tédio na vida cotidiana como princesinha rica, que tem que corresponder à exigência paterna "se não ele morreria de desgosto".

O pai é inserido numa lógica dissociativa: ela se mantém como objeto do narcisismo paterno diante de filha amorosa e dedicada, enquanto seus desejos 
incestuosos são atuados na máxima de sexo, drogas e rock and roll. Há também uma clivagem nesse pai dito amoroso: uma lembrança traumática da infância é evocada como um incidente em que pai tem uma crise de fúria e atira copos que poderiam atingi-la e matá-la, se ela não tivesse se desviado. Desta construção ou lembrança fica um ressentimento, e imenso ódio à mãe que não fez nada para defendê-la de um pai que não hesitaria em matá-la se tivesse "atingido" o alvo. Assim, nessa clivagem, o ódio é dirigido à mãe, por não conseguir exercer uma função de contenção e de limite a esse pai da horda, enquanto o pai é mantido como objeto idealizado, mas inacessível. Desviar-se da violência intrusiva do outro não é reconhecido por ela como um movimento de subjetivação, mas antes vivenciado como desamparo frente à omissão materna.

É interessante notar que este fragmento de sua infância é relacionado cronologicamente à idade de 7 anos, data de sua primeira experiência em análise, sugerindo que se a adolescência "é este momento de retorno de uma questão adiada” (PINHEIRO, 2001, p.71), o que retorna na análise de Maria não parece ser somente uma questão edipiana, mas principalmente uma problemática narcísica relacionada ao abandono e privação do objeto primordial.

Maria começa a beber descomedidamente, se envolvendo em acidentes que a deixam assustada, mas que a impelem a beber mais. Passamos por um longo tempo de abuso de álcool e de barbitúricos, overdoses no qual há sempre um limite tênue que separa suas encenações de morte/separação radical do objeto, e sua preocupação com o pai que poderia ter um enfarte se soubesse do que ela é capaz. "Se eu morrer, meu pai não vai aguentar, diz ela: se ele morrer, eu me mato" — oscilando entre manter um objeto intrusivo e tóxico e separar-se dele pela volta ao estado zero de tensão, ou seja, pela completa exclusão de si. A este respeito, vários autores indicam como na drogadição o verdadeiro tóxico não é a droga, mas sim uma intoxicação primária engendrada por falhas nas relações com os objetos primordiais (SAVIETTO, FIGUEIREDO \& SOUZA, 2013).

O uso que Maria faz do álcool e dos barbitúricos parece se relacionar a uma estratégia desesperada para dar contorno a sua agonia, pois, como indica Green, em contraposição a uma angústia de castração, há uma contradição formada pela dualidade de ansiedade de separação e de intrusão (GREEN, 1988). Assim, a cada episódio de overdose, Maria testa o efeito que provoca em seus pais - regozijando-se ante o desespero de sua mãe e de sua incapacidade de lhe dar limites, sentindo culpa e preocupação com seu pai, pois "poderia matá-lo de desgosto se morresse”. No entanto, o cansaço provocado nos outros por suas frequentes encenações abre uma brecha para a constatação de que o outro poderia viver sem ela, e propicia a abertura de um espaço potencial onde começa a reconhecer estratégias de separação em suas “atuações”, mesmo que pudessem 
também servir a um narcisismo de morte. É interessante pensar que a função desobjetalizante da pulsão de morte é também fundamental para estruturar os limites intra e interpsíquicos.

\section{CONSIDERAÇÕES FINAIS}

Pretendemos, neste texto, articular a problemática dos sofrimentos narcisico-identitários na adolescência às falhas nas relações objetais do início da vida, para discutir a função do objeto, assim como a importância do contexto/enquadre analítico (incluindo aí a capacidade de pensar e de sonhar do analista) para propiciar o acesso do sujeito adolescente aos processos de simbolização e introjeção.

Apesar de termos demonstrado que autores contemporâneos relacionam o momento da adolescência a um questionamento sobre os limites entre o eu e o outro, entre o interno e o externo, e nesta perspectiva, aproximam a clínica da adolescência à clínica dos casos-limite (CARDOSO, 2001; PINHEIRO, 2001), nosso objetivo foi indicar que o processo analítico na adolescência deve propiciar o acesso aos processos de simbolização que podem ser paralisados pela irrupção pulsional que impulsiona o sujeito à ação em detrimento da elaboração.

O fragmento clínico apresentado é paradigmático de uma clínica em que a noção da construção e da instauração de uma temporalidade contínua é fundamental, pois Maria foi atendida durante 20 anos permeados por longos intervalos que foram acolhidos como necessários e estruturantes, e não como resistências ou interrupções à análise e ao trabalho de apropriação subjetiva.

Assim como o caso de Maria, nossa observação clínica demonstra que muitas neuroses da infância são retomadas na adolescência não só pela possibilidade de retomar questões que possam ir além da sexualidade infantil e do autoerotismo, mas, principalmente, quando a constituição de uma neurose infantil como ponto culminante da organização psíquica do sujeito não se dá em função de falhas na relação aos objetos primordiais. Dessa forma, os “buracos psíquicos” resultantes de tais falhas produzem um recuo do trabalho de luto e reconhecimento da alteridade, e a incorporação funciona como defesa extrema contra a perda do objeto, impedindo o acesso aos processos de introjeção.

Como enuncia Roussillon (2010), para que o objeto possa ser simbolizado em sua alteridade, diferença e falta, é imprescindível a presença do próprio objeto, num jogo intersubjetivo que propicie um encontro entre o sujeito e seu duplo, desde que este "duplo" seja reconhecido como outro sujeito.

Ampliando a contribuição winnicottiana sobre a utilização do objeto na estruturação psíquica, o autor demonstra que o reconhecimento da alteridade depende da "resposta" do objeto à destrutividade do sujeito. Ou seja, não basta o objeto se mostrar psiquicamente presente sem retaliações ou confronto, pois 
é imprescindível que o objeto saia da órbita da destrutividade, mostrando-se “criativamente vivo" no encontro com o sujeito.

Assim, na clínica da adolescência e dos sofrimentos narcisico-identitários, é preciso que o objeto possa ser suficientemente semelhante para permitir a experiência de um prazer compartilhado, colocando-se ao mesmo tempo como objeto outro-sujeito que possibilite a descoberta da alteridade do outro, sem uma vivência de desamparo.

Manonni (2004), criticando a psicanálise por não contribuir muito para uma metapsicologia relativa à adolescência, ressalta que a análise com adolescentes deveria utilizar o brincar no sentido winnicottiano de propor um espaço potencial ao adolescente onde ele pudesse jogar com as diversas possibilidades identificatórias, desde que mantendo suas identificações primordiais, recortando-as ou complementando-as secundariamente, vivenciando uma relação de intersubjetividade sem risco de despersonalização ou morte psíquica.

Retomando a proposição de Laplanche (1992) ao ressaltar o aspecto sexual e enigmático do inconsciente do adulto nos cuidados veiculados à criança, podemos pensar que a adolescência reabre a questão do enigma, não só pela dimensão de interpelação que o confronto com a alteridade produz, mas também pela possibilidade de brincar com desconhecido e com o vazio. Assim, se a adolescência permite ir além da sexualidade infantil e reabre a capacidade de um trabalho do negativo, pretendemos enfatizar que esta capacidade só tem lugar na presença em reserva de um outro que possa reconhecer a função mensageira da pulsão, propiciando um encontro intersubjetivo que sirva de ancoragem para a capacidade de estar só (WINNICOTT, 1958/1990).

Recebido em 21/1/2014. Aprovado em 18/2/2014.

\section{REFERÊNCIAS}

ABRAHAM, N. \& TOROK, M. (1987) L'écorce et le noyau. Paris: Flammarion. CARDOSO, M. (2001) "Adolescência e violência: uma questão de 'fronteiras'”? , in Adolescência: reflexões psicanalíticas. Rio de Janeiro: Nau, p.41-55. FERENCZI, S. (1912/1955) "On the definition of Introjection", in Final contributions to the problems and methods of Psycho-analysis. New York: Brunner/ Mazel, p.316-318.

FIGUEIREDO, L.C. (2007) A metapsicologia do cuidado. Psyché, São Paulo, ano $11, \mathrm{n} .21, \mathrm{p} .13-30$.

FREUD, S. (1975) The standard edition of the complete psychological works of Sigmund Freud. London: Hogarth Press. 
(1909) "Analysis of a phobia in a five-year-old boy", v.X, p.3-148. (1917[1915]) "Mourning and melancholia”, v.XIV, p.237-243.

GREEN, A. (1988) "O analista, a simbolização e a ausência no contexto analítico”, in Sobre a loucura pessoal. Rio de Janeiro: Imago. p.36-65.

KHAN, M. R. (1971/1974) "Ouvir com os olhos: notas clínicas sobre o corpo como sujeito”, in Psicanálise, teoria, técnica e casos clínicos. Rio de Janeiro: Francisco Alves, p.285-304.

LAPLANCHE, J. (1992) Novos fundamentos para a psicanálise. São Paulo: Martins Fontes.

MANONNI, O. (2004) O adolescente é analisável? In: CORREA, A. (Org.). Mais tarde é agora! Salvador: Ágalma, p.19-34.

McDOUGALL, J. (2000) “Um corpo para dois”, in \& GACHELIN, G. et al. (Orgs.) Corpo e história. São Paulo: Casa do Psicólogo, p.9-45.

OGDEN, T. (1995). Os sujeitos da psicanálise. São Paulo: Casa do Psicólogo.

PINHEIRO, T. (2001) Narcisismo, sexualidade e morte, in CARDOSO, M. (Org.) Adolescência: reflexões psicanalíticas. Rio de Janeiro: Nau, p.69-81. RASSIAL, J. (1999) O adolescente e o psicanalista. Rio de Janeiro: Cia de Freud. ROUSSILLON, R. (1999) Agonie, clivage et symbolisation. Paris: PUF.

(2008) «La pulsion et l'intersubjectivité: vers l'entre-je(u)», in Le jeu et l'entre-je(u). Paris: PUF, p.1-22.

. (2010) La fonction symbolisante de l'objet, in GOLSE, B. \& ROUSSILLON, R. La naissance de l'objet. Paris: PUF, p.127-147.

SAVIETTO, B., FIGUEIREDO, L.C, SOUZA, O. (Orgs.). (2013). "Elasticidade e limite na clínica da drogadicção: por um pensamento clínico complexo", in. Elasticidade e limite na clínica contemporânea. São Paulo: Escuta, p.37-63.

URRIBARRI, F. (2010) Passion clinique, pensée complexe, in: GREEN, A. Illusions et désillusions du travail psychanalytique. Paris: Odile Jacob, p.243-269.

WINNICOTT, D. W. (1963/1990) "Comunicação e falta de comunicação levando ao estudo de certos opostos”, in O ambiente e os processos de maturação. Porto Alegre: Artes Médicas, p.163-174.

(1958/1990) "Capacidade para estar só", in O ambiente e os processos de maturação. Porto Alegre: Artes Médicas, p.31-38.

ZORNIG, S. (2008) A criança e o infantil em psicanálise. São Paulo: Escuta.

Silvia Maria Abu-Jamra Zornig

silvia.zornig@terra.com.br 